\title{
Third-Party Punishment Following Observed Social Rejection
}

\author{
Stephanie J. Dimitroff \\ University of Chicago
}

\author{
Ethan G. Harrod \\ University of Wisconsin-Madison
}

\author{
Karen E. Smith, Kelly E. Faig, Jean Decety, and Greg J. Norman \\ University of Chicago
}

\begin{abstract}
Humans routinely punish others for violating social norms. This behavior is referred to as third-party punishment. Much of the research on this topic has been done in the context of group cooperation and unjust economic interactions. However, little is known about punishment in response to other types of more personal transgressions. In the present study, we sought to determine whether adults would punish an individual after viewing them undeservingly reject a stranger. We experimentally demonstrate that after observing an individual socially reject an unknown victim, individuals will engage in third-party punishment. Individuals who reported feeling upset with the rejecter were most likely to punish, while feeling sorry for the victim was not predictive of punishment behavior. These findings highlight the motivational role of empathic anger in punishing social norm transgressors. Notably, individuals who reported having been bullied in their own pasts were the most likely to punish the rejecter. These results demonstrate how a history of being bullied may make one more attuned to the social rejection of others and in turn may make one more likely to take retributive action on behalf of another.
\end{abstract}

Keywords: third-party punishment, social rejection, empathic anger, bullying

Being intentionally wronged by others can have deleterious effects on a broad range of affective outcomes. However, such an aversive experience can also provide insight into the emotional state of others who experience similar events (Barnett, Tetreault, \& Masbad, 1987; Batson et al., 1996; Eklund, Andersson-Stråberg, \& Hansen, 2009; Hodges, Kiel, Kramer, Veach, \& Villanueva, 2010; Vollhardt, 2009). When observing another individual being victimized by unfair treatment, one's emotional response to the event, which may differ based on one's prior experiences of being victimized, may motivate one to intervene. For example, depending on one's own personal history with verbal abuse, observing such abuse occur to another individual may engender feelings of anger toward the offender or empathy toward the victim, which is likely to motivate different behavioral responses (e.g., helping the victim, punishing the perpetrator; Barnett et al., 1987; Batson et al., 1996; Eklund et al., 2009; Hodges et al., 2010; Vollhardt, 2009). While

Stephanie J. Dimitroff, Department of Psychology, Integrative Neuroscience Area, University of Chicago; Ethan G. Harrod, Department of Psychology, University of Wisconsin-Madison; Karen E. Smith, Kelly E. Faig, Jean Decety, and Greg J. Norman, Department of Psychology, Integrative Neuroscience Area, University of Chicago.

Karen E. Smith is now the Department of Psychology, University of Wisconsin-Madison.

Correspondence concerning this article should be addressed to Stephanie J. Dimitroff, who is now at Department of Clinical Neuropsychology, University of Konstanz, Universitätsstraße 10, Postfach 905, 78464 Konstanz, Germany. E-mail: stephanie-dimitroff@uni-konstanz.de choosing to console the victim can immediately benefit him or her, effectively punishing the perpetrator can have longer-lasting effects (Fehr \& Gächter, 2002). Although punishing wrongdoers is a high-risk behavior for a bystander (Alexander, 1974), it can act as a salient deterrent and potentially protect the victim and prospective victims from future unjust treatment (Carlsmith, Darley, \& Robinson, 2002; Fehr \& Gächter, 2002).

Third-party punishment has been posited to be a driving force for successful cooperative group living (Fowler, 2005). Similar to other social mammals, living in social groups helped better protect humans from predators and other humans and allowed division of labor for energetically demanding tasks such as hunting and foraging (Alexander, 1974). However, cooperating with group members would be disadvantageous if defectors were permitted to take advantage of communal benefits without contributing (Fowler, 2005). Therefore, it can be seen as adaptive, and even moral, to punish free-riders (Nelissen \& Zeelenberg, 2009). It has been experimentally demonstrated that, in groups where punishment is permitted, individuals will actively punish defectors, or social norm breakers, which then leads to an overall increase in group cooperation (Fehr \& Gächter, 2000, 2002). While there have been a number of studies that demonstrate the existence of third-party punishment in humans (e.g., Crockett, Clark, Lieberman, Tabibnia, \& Robbins, 2010; Shinada, Yamagishi, \& Ohmura, 2004; Vinkers et al., 2013), the results are mixed (Krasnow, Cosmides, Pedersen, \& Tooby, 2012; Pedersen, Kurzban, \& McCullough, 2013), and they have almost exclusively utilized economic games to create situations of unfairness. This methodology explicitly models unfair resource distribution, which is similar to some types of real-life 
social transactions but differs in nature from social-emotional injustices that involve personal devaluations. As such, the current work seeks to add to the literature by investigating whether a different type of unfairness, namely, unjustified social rejection, can also elicit third-party punishment.

One of the more psychologically distressing human experiences is feeling socially rejected by an individual or group (Baumeister \& Leary, 1995; Cacioppo et al., 2006). Social rejection refers to "a state of low relational evaluation in which a person does not regard his or her relationship with another individual as particularly valuable, important, or close" (Leary, 2001). Being rejected signals a potential threat to group membership, something that humans, like other nonhuman social mammals, are especially sensitive to as belonging to a group is essential for maintaining well-being and, ultimately, to survival. Following social rejection, individuals generally report depressed moods, sadness, and reductions in self-esteem (Blackhart, Eckel, \& Tice, 2007; Buckley, Winkel, \& Leary, 2004). Far from being an uncommon event, adults report feeling socially rejected on a regular basis (Nezlek, Wesselmann, Wheeler, \& Williams, 2012). Given the detrimental effects of being rejected, understanding how third parties react when observing someone else being unfairly rejected is important to understanding the complexities of social interactions. In these situations, third-party punishment involves acting against someone who is socially rejecting another in some way, instead of monetarily penalizing an unfair player by withholding resources, as has been shown in economic studies of this nature. Given this difference, it is currently unknown whether third parties would willingly get involved in such situations, as it involves punishing someone who is willing to psychologically harm others, as opposed to someone who is not willing to fairly share his or her resources.

Observing another individual being socially rejected has been shown to elicit similar feelings in the observer as in the actual person being rejected (Masten, Morelli, \& Eisenberger, 2011; Wesselmann, Bagg, \& Williams, 2009). This emotional overlap is especially present when observing others who we personally know (Wesselmann et al., 2009). However, experiencing empathy on behalf of the victim need not necessarily elicit a mirrored emotional state in the observer (Vitaglione \& Barnett, 2003). For example, if an individual observes the suffering of another that can be clearly attributed to a transgressor, that individual's empathic response may be represented by anger directed at the transgressor, instead of sadness on behalf of the victim (Vitaglione \& Barnett, 2003). This type of anger (empathic anger) has been demonstrated to increase the likelihood of engaging in helping and punishing behaviors measured via self-report (Vitaglione \& Barnett, 2003). Furthermore, work by Lotz, Okimoto, Schlösser, and Fetchenhauer (2011) has shown that third-party punishment in response to economic unfairness is more likely to occur if participants report feelings of moral outrage. As such, in some scenarios, empathic anger (or similar feelings of outrage) in an observer may result in the most beneficial outcome for the victim, because of its motivating nature to intervene.

This study aims to investigate whether third-party punishment occurs in response to viewing another individual being unfairly rejected. In contrast with past research on third-party punishment, we did not have participants witness an unfair economic decision but instead had them watch a realistic instance of someone being rejected. Participants were made to believe that they were observ- ing a true instance of social rejection happening between two (unbeknownst to them) fictitious experimental partners. The main goal of this study was to determine whether adults would thirdparty punish an individual who rejected a stranger. Additional goals included determining whether a history of being bullied (i.e., a similar past experience) would increase one's likelihood of punishing a rejecter and which emotional antecedents would be most predictive of third-party punishment (i.e., sadness on behalf of the victim vs. anger directed toward the rejecter).

\section{Method}

\section{Participants}

Eighty-three healthy volunteers between the ages of 18 and 25 ( $M=19.90, S D=1.59,49$ female, 39 Caucasian) were brought into the lab as part of a larger study on observed social rejection. $\mathrm{G}^{*}$ Power analyses suggested a minimum sample size of 60 to obtain statistical power of 0.80 and a medium effect size $(f=$ 0.25). All participants were recruited via the University of Chicago's online internal psychological recruitment system (SONA). We posted a larger number of sign-ups than required for adequate power due to anticipated no-shows. We obtained $n=83$ by honoring all sign ups. Participants were instructed to refrain from consuming caffeine or participating in strenuous activity for $2 \mathrm{hr}$ prior to participation. All participants provided written informed consent as approved by the University of Chicago Institutional Review Board and were paid or given course credit for their participation.

\section{Procedure}

The study protocol was approved by the University of Chicago Institutional Review Board. Participants first answered a survey of general demographic information and completed a set of psychological questionnaires, including the Psychopathy Personality Inventory (Benning, Patrick, Hicks, Blonigen, \& Krueger, 2003) and the Questionnaire of Cognitive and Affective Empathy (Reniers, Corcoran, Drake, Shryane, \& Völlm, 2011). Participants were then seated in a chair in front of a 39-inch TV with a webcam installed on top of it. The experimenter informed participants that the aim of the present study was to determine how people perceive and judge others and how these perceptions and judgments inform their friendship-making decisions. Participants were told that in order to test this, they would be partaking in the experiment with two other individuals who are located in two other nearby testing rooms (these participants were fictitious), and that in order to "meet" one another, they would all be videotaped and then watch each other's video tapes as a means of introduction. Participants were provided with a prompt for the speech they were going to give on camera for their introduction; they were asked to talk for $2 \mathrm{~min}$ about their morning routine. This prompt was chosen due to its unemotional nature. Once the video was recorded, the experimenter pretended to save the video file onto a USB key and then left the room, telling the participant they would go deliver their video and collect the videos of the two other participants. After approximately a minute, the experimenter returned and played two prerecorded 1-min-long videos (on the topic of morning routines), under the ruse that the speakers were the participants in the other room. Four videos (one 
male pair and one female pair) were selected from a larger stimulus set of videos of individuals being recorded talking about their morning routines. All participants viewed recordings of same-sex individuals and were told that one individual is "Participant A" and the other is "Participant B." The order of the videos, as well as which video was assigned to be A or B, was counterbalanced across trials. Participants were then told that Participant A was randomly assigned to be judged and that they, along with Participant $\mathrm{B}$, were to act as judges. Participants were then given two copies of a questionnaire we created for the purpose of this experiment entitled the Perceived Likeability Questionnaire (PLQ). The PLQ was composed of 12 multiple-choice questions designed to allow participants to answer questions about another individual's social desirability (see online supplemental materials). Questions included assessment of the target person's attractiveness, intelligence, and likability as a friend. Participants were told to fill out two identical copies of the PLQ about Participant A, one to be delivered to Participant A so they could see ratings about themselves and the other to Participant B so they could compare opinions about Participant A. Once participants completed the two PLQs and placed them in two manila folders, the experimenter collected their questionnaires and left the room to ostensibly deliver them and retrieve Participant B's PLQ about Participant A. While outside the room, the experimenter retrieved a precompleted PLQ (Participant B's), which served as the experimental manipulation of this study. A score of $100 \%$ on the PLQ would indicate all responses chosen were the most positive. The precompleted PLQs were either $90 \%$ positive (representing the control condition) or $27 \%$ positive (the experimental condition). This social rejection manipulation is similar to the one used by Buckley et al. (2004). Within condition, the responses to all PLQ questions were identical. Prior to the start of the study, all precompleted PLQs were inserted into individual manila folders and shuffled. Thus, when the experimenter retrieved the manila folder, he or she did not know the contents, which ensured a double-blind procedure. The experimenter then returned to the testing room, gave the participant the PLQ in the manila folder, and instructed him or her to read Participant B's judgment of Participant A.

Once participants indicated that they were finished reading, they were informed about the second phase of the experiment, which involved "playing games" with Participants A and B. Their first task was a sound blast paradigm programmed in E-Prime 2.0 (Psychology Software Tools, Pittsburgh, PA). Participants were told that they would be playing a social cognition game, and they were assigned to be the "distributor" while Participants A and B were assigned to be players. Participants were randomly assigned to play with either Participant A or B first and were led to believe that they were seeing the player's screen mirrored on the screen in front of them. The screen quickly displayed a series of 12 neutral faces, followed by a series of 3 faces, and participants believed that the player had to indicate whether all 3 faces were a part of the previous 12. After each trial, participants were able to see whether the player was correct or incorrect. When they were incorrect, a volume bar appeared, and participants were able to adjust the volume of a sound blast that the player would then receive through headphones. At the onset of the game, participants were made to hear what the sound blast sounded like when set to the middle of the bar. Participants played 10 trials with each player. Five of these trials were programmed to be incorrect responses. Participants then played a two-recipient dictator game where they were able to distribute \$10 USD among themselves and Participants A and B in any way of their choosing.

After the two games, participants completed a closing survey on a laptop. The closing survey included questions about their history of being bullied, similar to those used in previous research (Brunstein Klomek, Marrocco, Kleinman, Schonfeld, \& Gould, 2007; Flaspohler, Elfstrom, Vanderzee, Sink, \& Birchmeier, 2009; Tehrani, 2004), how sorry they felt for Participant A, how upset they felt with Participant B, and how believable the felt the study to be. All closing survey questions can be found in the online supplemental materials. Finally, participants were debriefed and compensated the money they earned from the dictator game and either $\$ 10$ or 1 course credit for their participation.

\section{Statistical Analysis}

All data were analyzed using IBM SPSS (SPSS, Inc., Chicago, IL). Sound blast volumes were on a scale of $0-100$. Sound blasts volumes were averaged over the five error trials. If average sound blast volumes or money allocation were over 3 standard deviations from the mean, data were considered outliers and were thus excluded. There were two outliers removed from sound blast data, and no outliers were found for money allocation. An additional two participants had lost data, one whose sound blast data were lost and one whose closing survey answers were not recorded. Experimental condition was coded as a 0/1 dummy variable. Bullying history was coded as a categorical variable with three levels: yes, no, and maybe. Emotional responses to observing the rejection (feeling upset with the rejecter and feeling sorry for the victim) were coded as ordinal variables (ranging from no, not really, somewhat, and definitely yes). All multiple comparisons performed were Bonferroni corrected at $p<.05$. Effect sizes are reported using partial $\eta^{2}$, which represents the proportion of the effect plus error variance that is attributable to the effect (Lakens, 2013). Results of analyses relating to dispositional empathy and psychopathy can be found in the online supplemental materials.

\section{Results}

For explanatory purposes, Participant A will be referred to as the victim, and Participant $\mathrm{B}$ will be referred to as the rejecter across conditions.

A two-way mixed measures analysis of variance (ANOVA) revealed a significant interaction effect between experimental condition and player (rejecter/victim) in volume of sound blasts administered, $F(1,78)=9.94, p=.002, \eta^{2}=0.11$ (see Figure 1). A post hoc paired $t$ test revealed that participants administered significantly louder sound blasts to the rejecter, as compared to the victim, in the experimental condition, $t(39)=3.20, p=.002$, two-tailed, $d=0.51$. This difference remained significant after Bonferroni correction. A post hoc $t$ test also revealed louder volumes were administered to the rejecter in the experimental condition as compared to the control condition, $t(78)=2.31, p=$ .024 , two-tailed, $d=0.52$, but the difference did not pass Bonferroni correction. The difference in volumes was not significant in the control condition, $t(39)=0.30, p=.767$, two-tailed, $d=0.05$.

A two-way mixed-measures ANOVA revealed a significant interaction effect between experimental condition and experimen- 


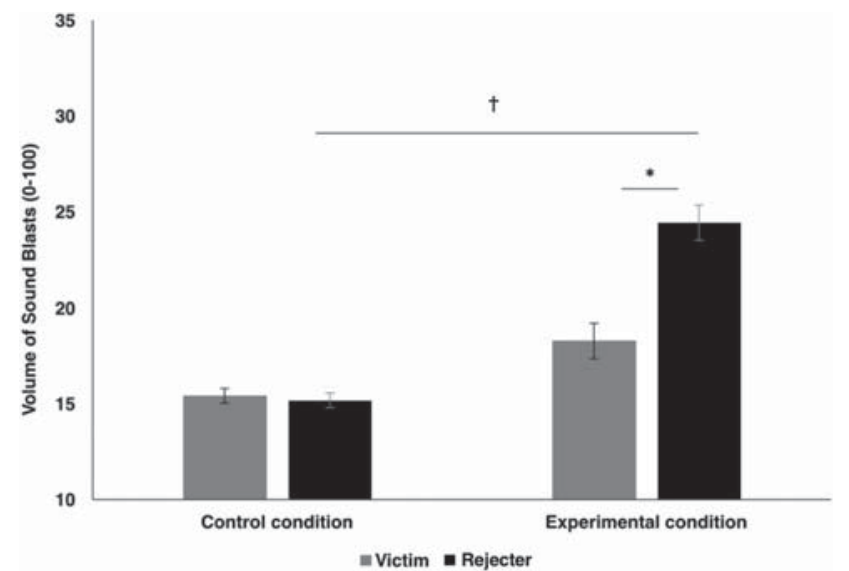

Figure 1. Volume of sound blasts administered to rejecter and victim in control and experimental conditions. Error bars represent within-subjects $95 \%$ confidence intervals. The asterisk represents a significant difference after Bonferroni correction $(p<.05)$. The cross represents a difference of $p<.05$, which did not survive Bonferroni correction.

tal player (rejecter/victim) in amount of money given away in the dictator game, $F(1,81)=8.09, p=.006, \eta^{2}=0.09$ (see Figure 2). A post hoc paired $t$ test revealed that participants distributed significantly less money to the rejecter compared to the victim in the experimental condition, $t(42)=3.09, p=.004$, two-tailed, $d=$ 0.40 . This comparison did not change after Bonferroni correction. A post hoc $t$ test also revealed a trend of less money given to the rejecter in the experimental condition as compared to the control condition, $t(81)=1.91, p=.060$, two-tailed, $d=0.42$. The difference in money allocation was not significant in the control condition, $t(39)=0.57, p=.574$, two-tailed, $d=0.09$.

There was a significant correlation between the difference in volume administered to rejecter and victim and the difference in money given to rejecter and victim in the experimental condition, $r(40)=-0.66, p<.01$, while the same correlation was not significant in the control group, $r(40)=-0.04, p=.79$ (see Figure 3).

A three-way mixed measures ANOVA with the dependent variables being volume to rejecter and victim was performed with the between-subject variables of experimental condition and bullying history (categorical variable coding for responses yes/no/maybe to question "were you bullied in your past?"). Bullying history significantly interacted with volume difference and condition, $F(2$, 73 ) $=6.29, p=.003, \eta^{2}=0.15$ (see Figure 4). A paired samples post hoc $t$ test revealed that in the experimental condition, participants who reported being bullied in the past gave significantly louder blasts to the rejecter as compared to the victim, $t(17)=$ 3.52, $p=.003, d=0.83$. This comparison survived Bonferroni correction. There was no significant difference in experimental condition volumes in participants who reported no past of bullying, $t(12)=0.95, p=.361, d=0.06$. For additional analyses including bullying history, please see the online supplemental materials.

A three-way mixed measures ANOVA with the dependent variables being money given to rejecter and victim was performed with the between-subject variables of experimental condition and bullying history. A trending interaction was observed between money allocation, experimental condition, and bullying history, $F(2,76)=2.41, p=.097, \eta^{2}=0.06$.

Finally, we conducted analyses with the closing survey questions, "Did you feel sorry for the participant who was judged?" and "Did you feel upset with the other judge?" Response options were "definitely yes," "somewhat," "not really," and "no," which we coded numerically as ordinal variables. One-way ANOVAs revealed that participants felt more sorry for the victim, $F(1,80)=$ $11.22, p=.001, \eta^{2}=0.12$, and felt more upset with the rejecter, $F(1,80)=60.36, p<.001, \eta^{2}=0.43$, in the experimental condition. These ratings support our experimental manipulation as being successful in inducing emotional reactions to observed social rejection in our participants. To determine whether feeling sorry for the victim or feeling upset with the rejecter predicted third-party punishment behavior, we conducted four two-way mixed-measure ANOVAs with feeling sorry or feeling upset as between-subjects factors: Volume Difference $\times$ Feeling Sorry, Volume Difference $\times$ Feeling Upset, Money Difference $\times$ Feeling Sorry, and Money Difference $\times$ Feeling Upset. We did not run these two factors in the same model because these variables were highly correlated with one another, $r(82)=0.52, p<.001$. Feeling sorry for the victim, $F(3,75)=2.09, p=.109, \eta^{2}=0.07$, did not predict any volume differences, but feeling upset with the rejecter did, $F(3,75)=11.52, p<.001, \eta^{2}=0.32$. A paired samples post hoc $t$ test revealed that participants who reported feeling upset with the rejecter (indicated by replies "definitely yes" and "somewhat") gave significantly louder blasts to the rejecter as compared to the victim, $t(23)=3.87, p=.001$, two-tailed, $d=0.79$. This difference remained significant after Bonferroni correction. There was no significant difference in volume blasts administered by participants who reported not feeling upset with the rejecter (responses "no" and "not really"), $t(52)=0.79, p=.433$, two-tailed, $d=$ 0.11 . Feeling sorry for the victim also did not predict differences in money allocation, $F(3,78)=1.92, p=.134, \eta^{2}=0.07$. However, feeling upset with the rejecter did, $F(3,78)=15.26, p<$ $.001, \eta^{2}=0.37$. A paired samples post hoc $t$ test revealed that

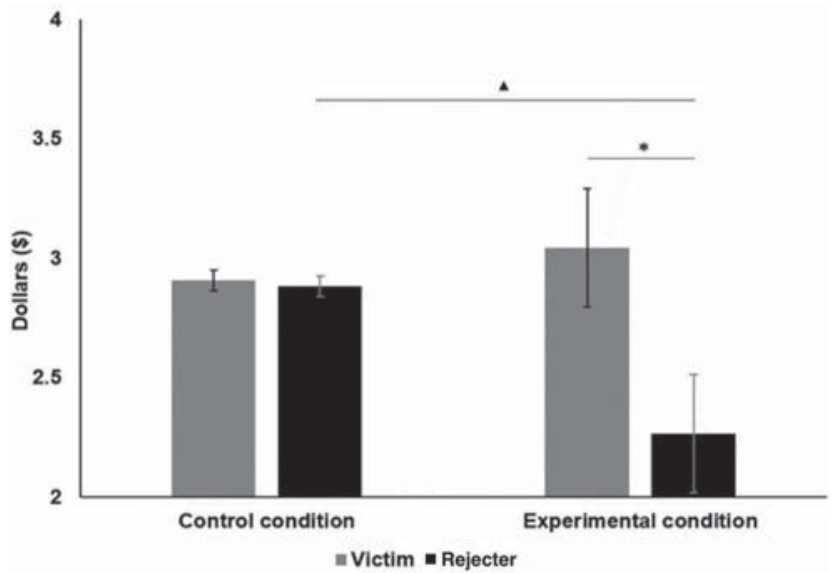

Figure 2. Amount of money (out of $\$ 10$ ) given to victim and rejecter in a two-person dictator game in control and experimental conditions. Error bars represent within-subjects $95 \%$ confidence intervals. The asterisk represents a significant difference after Bonferroni correction $(p<.05)$ and the triangle represents a trending difference between conditions $(p=.06)$. 


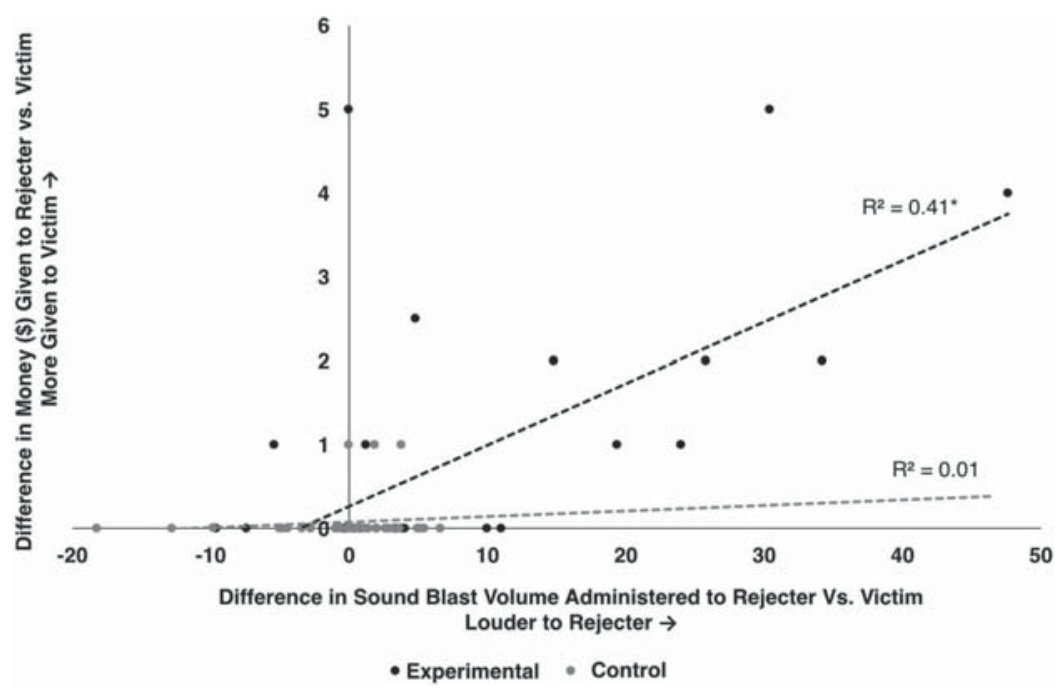

Figure 3. Correlation between the difference in volume of sound blasts administered to rejecter versus victim and the difference in amount of money given to rejecter versus victim in control and experimental conditions. The asterisk represents a significant correlation $(p<.05)$.

participants who reported feeling upset with the rejecter gave significantly less money to the rejecter as compared to the victim, $t(25)=3.48, p=.002$, two-tailed, $d=0.68$. This difference remained significant after Bonferroni correction. There was no significant difference in volume blasts administered by participants who reported not feeling upset with the rejecter, $t(53)=$ $0.01, p=.996$, two-tailed, $d=0$. The volume administered to the rejecter as compared to the victim in the experimental condition was significantly correlated with self-report upset ratings, $r_{\mathrm{s}}(42)=$ $0.42, p=.009$ (see Figure 5). The difference in money given to the victim as compared to the rejecter in the experimental condition was also significantly correlated with participants' self-report upset ratings, $r_{\mathrm{s}}(42)=0.61, p<.001$. Feeling sorry for the victim was not correlated with either outcome variable, $p>.05$ (see Figure 5).

In the experimental condition, participants who reported feeling sorry for the victim did not differ in terms of their past bullying history, $r_{\mathrm{s}}(42)=0, p=.993$. Similarly, in the experimental condition, participants who reported feeling upset with the rejecter also did not differ in terms of their history of being bullied, $r_{\mathrm{s}}(42)=0.22, p=.160$.

We also scored all PLQs filled out by participants to ensure no participants independently acted as rejecters. The average score was $74 \%$ positive, with a range of $47 \%-98 \%$, which confirmed no participants were as negative as the rejecter in the experimental condition. A one-way ANOVA revealed that there was no effect of bullying history on participants' PLQ scores, $F(2,79)=0.95, p=$ .391, $\eta^{2}=0.02$. We ran two two-way mixed model ANOVAs with volume difference and money difference as dependent variables and PLQ scores as a covariate. PLQ scores were not predictive of any later behavior on these measures, $p>.05$.

As a final manipulation check, participants were asked to rate how believable they thought the experiment was on a scale from 1 to 7. Median participant ratings were "3," which represented a)

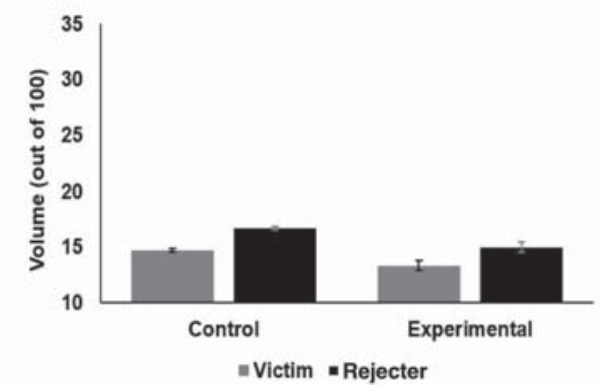

b)

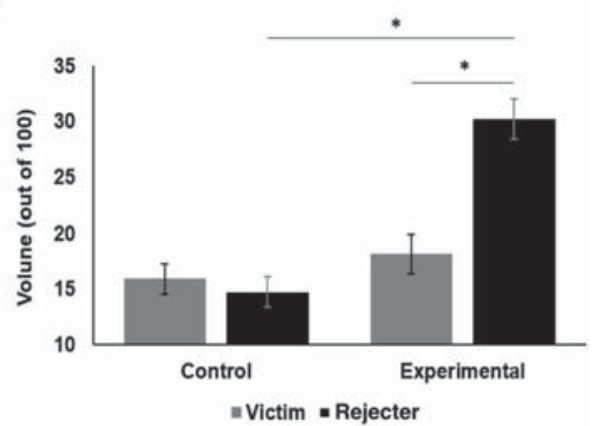

Figure 4. In participants who reported no history of being bullied, (a) volume of sound blasts administered to rejecter and victim in control and experimental conditions. In participants who reported a history of being bullied (b), volume of sound blasts administered to rejecter and victim in control and experimental condition. Error bars represent within-subjects $95 \%$ confidence intervals. The asterisk represents a significant difference after Bonferroni correction $(p<.05)$. 
a)

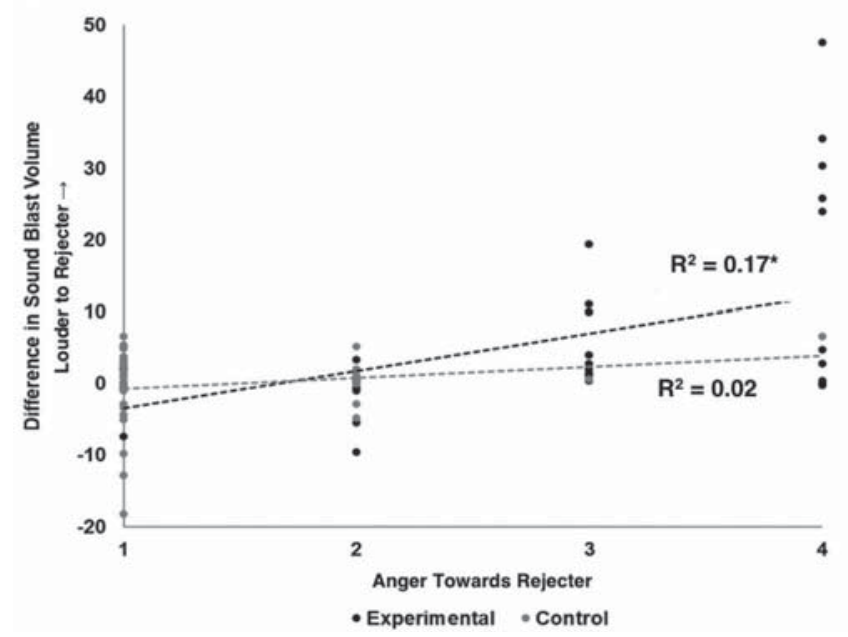

b)

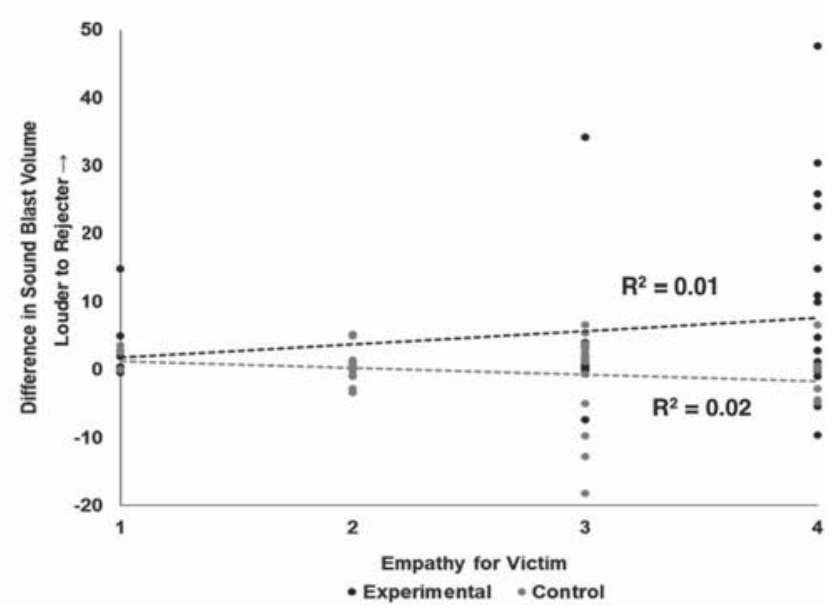

Figure 5. Participants self-reported feelings of anger toward the rejecter (a) and difference in volume of sound blasts administered to rejecter versus victim in control and experimental conditions. Participants self-reported feelings of empathy toward the victim (b) and difference in amount of money allocated to rejecter versus victim in control and experimental conditions. The asterisk represents a significant correlation $(p<.05)$.

"slightly believable," and the average score was 3.77 , which was between "slightly believable" and "neutral." There was no significant effect of condition on believability scores, $F(1,80)=1.53$, $p=.220, \eta^{2}=0.02$.

\section{Discussion}

Third-party punishment behavior was observed in adults after viewing a stranger be socially rejected by another. Our findings add to the literature by supporting the case for third-party punishment by demonstrating that third parties will actively punish others, in this case, for undeserved social rejection. These results were found between adult strangers, despite recent work that has suggested punishment of a third party necessitates a relationship with the victim (Gürǒ Glu, Will, \& Klapwijk, 2013; Pedersen, McAuliffe, \& McCullough, 2018). As such, rejection may be more salient than other types of observed injustices (e.g., economical unfairness) and be enough to elicit proactive aggression toward a transgressor even in the absence of a relationship to the victim. In the present study, participants administered louder sound blasts and gave less money to the rejecter, despite these actions having no immediate benefit to themselves. Recent work by Pedersen et al. (2018) found no evidence for third-party punishment in response to observed social rejection. However, the current study used more personal methods for creating a scenario more in line with real-life social rejection. The participant observed the rejecter evaluate the victim as someone he or she judged to be uninteresting, lazy, unintelligent, and not someone he or she was interested in being friends with. Previous research has indicated that the most hurtful types of rejection are most commonly those that target one's social desirability (Leary, Springer, Negel, Ansell, \& Evans, 1998), which is why the PLQ was designed as a questionnaire to assess one's attractiveness as a friend. Furthermore, participants were introduced to one another via video prior to the experimental manipulation. By relating Pedersen et al.'s (2018) results with our own, we can surmise that third-party punishment behavior can occur in response to observed social rejection, but individuals may need to have some familiarly with victims (in our case, via video introduction), and the rejection must be personally directed and relatively intense.

Interestingly, our results demonstrate how having a history of being bullied greatly increases one's odds of punishing a rejecter, which highlights the importance past experience can have on how one reacts to another's distress. One likely explanation for these results is that a history of having been bullied not only is associated with increased personal rejection sensitivity (Butler, Doherty, $\&$ Potter, 2007) but is also potentially associated with an increased sensitivity for the rejection of others. Given the numerous negative impacts childhood bullying has on adults (Copeland et al., 2014; Sansone, Watts, \& Wiederman, 2014; Takizawa, Maughan, \& Arseneault, 2014; Wolke, Copeland, Angold, \& Costello, 2013), these results offer a new perspective to such findings. Indeed, individuals who have had similar negative experiences to you might be the ones most likely to seek retribution on your behalf. An additional explanation could also be that those who have been bullied are more likely to generally act more aggressively toward others, given research that has shown victims of bullies are less trusting, are more dishonest, and have poorer social development (Andreou, 2004; Perren \& Alsaker, 2006; Takizawa et al., 2014). However, the data we have are not consistent with this line of reasoning as we found no effect of bullying history on aggressive behavior in the control condition, where no rejection was observed, and bullying history did not predict how participants rated the victim on the PLQ. Our findings were clear in that bullying history did not predict general aggressive behavior, only aggressive behavior in line with third-party punishment. This finding provides support for the theory of "altruism born of suffering" (Vollhardt, 2009), which posits that experiencing an aversive or traumatic event may then make one more likely to help others in 
similar situations. Intriguingly, bullying history was mostly related to third-party punishment via sound blasts and not via money allocation. This highlights how these two modes of punishment are likely motivated by different psychological variables and how one's willingness to engage in "passive" punishment, like withholding money, may not directly map onto one's willingness to engage in a more "active" punishment, like administering an aversive sound blast. Future research should explore motivational differences between these two types of punishing behavior.

Feeling sorry for the victim was also not related to third-party punishment behavior. On the other hand, feeling upset with the rejecter was predictive of third-party punishment behavior. This is in line with previous work by Fehr and Fischbacher (2004), which found that feelings of anger predicted punishment of a defector. These findings illustrate how third-party punishment is not strongly related to feelings of sadness on behalf of victims. In contrast, it is likely instigated by empathic anger. Future work will be necessary to further understand which interindividual differences predispose an individual to experience empathic anger toward a transgressor.

One limitation of this study is that it was conducted with University of Chicago students, which, in addition to limiting generalizability, also leads to the question of whether behavior would have differed had participants not perceived the rejecter and victim to be part of their "in-group." Our study also only investigated same-sex triads, so these results do not speak to how behavior might change when interacting with individuals of the opposite sex. Furthermore, the design of the current study does not allow for us to conclusively determine that our results are specific to observing someone socially reject an individual or if these results reflect how individuals respond when observing negative information about another person on a broader level (e.g., lying to someone). Finally, our paradigm allowed participants to act along a continuum and did not involve a forced choice or helping or punishing. In real-life situations, one's choice would often be dichotomous - namely, to help the victim or punish the rejecter. Future research is required to be able determine how individuals act when they must choose one action over another.

This article provides evidence that adults who witness a stranger being unfairly socially rejected will seek retributive justice. This behavior is likely motivated by empathic anger and is especially found in individuals who report having been bullied in the past. This suggests that while having been bullied can result in a slew of negative outcomes later in life, it may also come with the side effect of making one more likely to step in when observing someone else experience a similar rejection. Third-party punishment is an essential part of maintaining social cohesion within a group, as it discourages violations of social norms and serves as a form of helping behavior. Within social groups, there are always individuals who are treated unfairly and others who witness it. It is important for future research to continue exploring how individuals react to the observation of such unfair treatment. The more we understand about how individuals react to the unfair treatment of others, the better we can identify the types of interventions that will lead to more favorable outcomes for victims and the larger group.

\section{References}

Alexander, R. D. (1974). The evolution of social behavior. Annual Review of Ecology and Systematics, 5, 325-383. http://dx.doi.org/10.1146/annurev.es .05 .110174 .001545
Andreou, E. (2004). Bully/victim problems and their association with Machiavellianism and self-efficacy in Greek primary school children. British Journal of Educational Psychology, 74(Pt 2), 297-309. http://dx .doi.org/10.1348/000709904773839897

Barnett, M. A., Tetreault, P. A., \& Masbad, I. (1987). Empathy with a rape victim: The role of similarity of experience. Violence and Victims, 2, 255-262. http://dx.doi.org/10.1891/0886-6708.2.4.255

Batson, C. D., Sympson, S. C., Hindman, J. L., Decruz, P., Todd, R. M., Weeks, J. L., . . . Burns, C. T. (1996). "I've been there, too" effect on empathy of prior experience with a need. Personality and Social Psychology Bulletin, 22, 474-482. http://dx.doi.org/10.1177/0146167296225005

Baumeister, R. F., \& Leary, M. R. (1995). The need to belong: Desire for interpersonal attachments as a fundamental human motivation. Psychological Bulletin, 117, 497-529. http://dx.doi.org/10.1037/0033-2909.117 .3 .497

Benning, S. D., Patrick, C. J., Hicks, B. M., Blonigen, D. M., \& Krueger, R. F. (2003). Factor structure of the psychopathic personality inventory: Validity and implications for clinical assessment. Psychological Assessment, 15, 340-350. http://dx.doi.org/10.1037/1040-3590.15.3.340

Blackhart, G. C., Eckel, L. A., \& Tice, D. M. (2007). Salivary cortisol in response to acute social rejection and acceptance by peers. Biological Psychology, 75, 267-276. http://dx.doi.org/10.1016/j.biopsycho.2007.03 .005

Brunstein Klomek, A., Marrocco, F., Kleinman, M., Schonfeld, I. S., \& Gould, M. S. (2007). Bullying, depression, and suicidality in adolescents. Journal of the American Academy of Child \& Adolescent Psychiatry, 46, 40-49. http://dx.doi.org/10.1097/01.chi.0000242237.84925.18

Buckley, K. E., Winkel, R. E., \& Leary, M. R. (2004). Reactions to acceptance and rejection: Effects of level and sequence of relational evaluation. Journal of Experimental Social Psychology, 40, 14-28. http://dx.doi.org/10.1016/S0022-1031(03)00064-7

Butler, J. C., Doherty, M. S., \& Potter, R. M. (2007). Social antecedents and consequences of interpersonal rejection sensitivity. Personality and Individual Differences, 43, 1376-1385. http://dx.doi.org/10.1016/j.paid .2007 .04 .006

Cacioppo, J. T., Hawkley, L. C., Ernst, J. M., Burleson, M., Berntson, G. G., Nouriani, B., \& Spiegel, D. (2006). Loneliness within a nomological net: An evolutionary perspective. Journal of Research in Personality, 40, 1054-1085. http://dx.doi.org/10.1016/j.jrp.2005.11.007

Carlsmith, K. M., Darley, J. M., \& Robinson, P. H. (2002). Why do we punish? Deterrence and just deserts as motives for punishment. Journal of Personality and Social Psychology, 83, 284-299. http://dx.doi.org/10 1037/0022-3514.83.2.284

Copeland, W. E., Wolke, D., Lereya, S. T., Shanahan, L., Worthman, C., \& Costello, E. J. (2014). Childhood bullying involvement predicts low-grade systemic inflammation into adulthood. Proceedings of the National Academy of Sciences of the United States of America, 111, 7570-7575. http://dx.doi.org/10.1073/pnas.1323641111

Crockett, M. J., Clark, L., Lieberman, M. D., Tabibnia, G., \& Robbins, T. W. (2010). Impulsive choice and altruistic punishment are correlated and increase in tandem with serotonin depletion. Emotion, 10, 855-862. http://dx.doi.org/10.1037/a0019861

Eklund, J., Andersson-Stråberg, T., \& Hansen, E. M. (2009). "I've also experienced loss and fear": Effects of prior similar experience on empathy. Scandinavian Journal of Psychology, 50, 65-69. http://dx.doi .org/10.1111/j.1467-9450.2008.00673.x

Fehr, E., \& Fischbacher, U. (2004). Third party punishment and social norms. Evolution and Human Behavior, 25, 63-87. http://dx.doi.org/10 .1016/S1090-5138(04)00005-4

Fehr, E., \& Gächter, S. (2000). Cooperation and punishment in public goods experiments. American Economic Review, 90, 980-994. http://dx .doi.org/10.1257/aer.90.4.980

Fehr, E., \& Gächter, S. (2002). Altruistic punishment in humans. Nature, 415, 137-140. http://dx.doi.org/10.1038/415137a 
Flaspohler, P. D., Elfstrom, J. L., Vanderzee, K. L., Sink, H. E., \& Birchmeier, Z. (2009). Stand by me: The effects of peer and teacher support in mitigating the impact of bullying on quality of life. Psychology in the Schools, 46, 636-649. http://dx.doi.org/10.1002/pits.20404

Fowler, J. H. (2005). Altruistic punishment and the origin of cooperation. Proceedings of the National Academy of Sciences of the United States of America, 102, 7047-7049. http://dx.doi.org/10.1073/pnas.0500938102

Gürǒ Glu, B., Will, G.-J., \& Klapwijk, E. T. (2013). Some bullies are more equal than others: Peer relationships modulate altruistic punishment of bullies after observing ostracism. International Journal of Developmental Science, 7, 13-23.

Hodges, S. D., Kiel, K. J., Kramer, A. D. I., Veach, D., \& Villanueva, B. R. (2010). Giving birth to empathy: The effects of similar experience on empathic accuracy, empathic concern, and perceived empathy. Personality and Social Psychology Bulletin, 36, 398-409. http://dx.doi.org/10 $.1177 / 0146167209350326$

Krasnow, M. M., Cosmides, L., Pedersen, E. J., \& Tooby, J. (2012). What are punishment and reputation for? PLoS ONE, 7, e45662. http://dx.doi .org/10.1371/journal.pone.0045662

Lakens, D. (2013). Calculating and reporting effect sizes to facilitate cumulative science: A practical primer for t-tests and ANOVAs. Frontiers in Psychology, 4, 863. http://dx.doi.org/10.3389/fpsyg.2013.00863

Leary, M. R. (Ed.). (2001). Toward a conceptualization of interpersonal rejection. In Interpersonal rejection (pp. 3-20). New York, NY: Oxford University Press.

Leary, M. R., Springer, C., Negel, L., Ansell, E., \& Evans, K. (1998). Calibrating the sociometer: The relationship between interpersonal appraisals and state self-esteem. Journal of Personality and Social Psychology, 74, 1225-1237. http://dx.doi.org/10.1037/0022-3514.74.5.1225

Lotz, S., Okimoto, T. G., Schlösser, T., \& Fetchenhauer, D. (2011). Punitive versus compensatory reactions to injustice: Emotional antecedents to third-party interventions. Journal of Experimental Social Psychology, 47, 477-480. http://dx.doi.org/10.1016/j.jesp.2010.10.004

Masten, C. L., Morelli, S. A., \& Eisenberger, N. I. (2011). An fMRI investigation of empathy for 'social pain' and subsequent prosocial behavior. NeuroImage, 55, 381-388. http://dx.doi.org/10.1016/j.neuroimage.2010.11 .060

Nelissen, R. M. A., \& Zeelenberg, M. (2009). Moral emotions as determinants of third-party punishment: Anger, guilt, and the functions of altruistic sanctions. Judgment and Decision Making, 4, 543-553.

Nezlek, J. B., Wesselmann, E. D., Wheeler, L., \& Williams, K. D. (2012). Ostracism in everyday life. Group Dynamics: Theory, Research, and Practice, 16, 91-104. http://dx.doi.org/10.1037/a0028029

Pedersen, E. J., Kurzban, R., \& McCullough, M. E. (2013). Do humans really punish altruistically? A closer look. Proceedings of the Royal Society B, Biological Sciences, 280, 20122723. http://dx.doi.org/10 .1098/rspb.2012.2723

Pedersen, E. J., McAuliffe, W. H. B., \& McCullough, M. E. (2018). The unresponsive avenger: More evidence that disinterested third parties do not punish altruistically. Journal of Experimental Psychology: General, 147, 514-544. http://dx.doi.org/10.1037/xge0000410

Perren, S., \& Alsaker, F. D. (2006). Social behavior and peer relationships of victims, bully-victims, and bullies in kindergarten. Journal of Child Psychology and Psychiatry, 47, 45-57. http://dx.doi.org/10.1111/j.14697610.2005.01445.x

Reniers, R. L. E. P., Corcoran, R., Drake, R., Shryane, N. M., \& Völlm, B. A. (2011). The QCAE: A questionnaire of cognitive and affective empathy. Journal of Personality Assessment, 93, 84-95. http://dx.doi .org/10.1080/00223891.2010.528484

Sansone, R. A., Watts, D. A., \& Wiederman, M. W. (2014). Being bullied in childhood, and pain and pain perception in adulthood. International Journal of Social Psychiatry, 60, 449-453. http://dx.doi.org/10.1177/ 0020764013495526

Shinada, M., Yamagishi, T., \& Ohmura, Y. (2004). False friends are worse than bitter enemies: Altruistic punishment of in-group members. Evolution and Human Behavior, 25, 379-393. http://dx.doi.org/10.1016/j.evolhumbehav.2004.08.001

Takizawa, R., Maughan, B., \& Arseneault, L. (2014). Adult health outcomes of childhood bullying victimization: Evidence from a five-decade longitudinal British birth cohort. American Journal of Psychiatry, 171, 777-784. http://dx.doi.org/10.1176/appi.ajp.2014.13101401

Tehrani, N. (2004). Bullying: A source of chronic post traumatic stress? British Journal of Guidance \& Counselling, 32, 357-366. http://dx.doi .org/10.1080/03069880410001727567

Vinkers, C. H., Zorn, J. V., Cornelisse, S., Koot, S., Houtepen, L. C., Olivier, B., . . . Joëls, M. (2013). Time-dependent changes in altruistic punishment following stress. Psychoneuroendocrinology, 38, 14671475. http://dx.doi.org/10.1016/j.psyneuen.2012.12.012

Vitaglione, G. D., \& Barnett, M. A. (2003). Assessing a new dimension of empathy: Empathic anger as a predictor of helping and punishing desires. Motivation and Emotion, 27, 301-325. http://dx.doi.org/10.1023/ A: 1026231622102

Vollhardt, J. R. (2009). Altruism born of suffering and prosocial behavior following adverse life events: A review and conceptualization. Social Justice Research, 22, 53-97. http://dx.doi.org/10.1007/s11211-009-0088-1

Wesselmann, E. D., Bagg, D., \& Williams, K. D. (2009). "I feel your pain”: The effects of observing ostracism on the ostracism detection system. Journal of Experimental Social Psychology, 45, 1308-1311. http://dx doi.org/10.1016/j.jesp.2009.08.003

Wolke, D., Copeland, W. E., Angold, A., \& Costello, E. J. (2013). Impact of bullying in childhood on adult health, wealth, crime, and social outcomes. Psychological Science, 24, 1958-1970. http://dx.doi.org/10 $.1177 / 0956797613481608$ 